\title{
The Pressure-Status Nexus and Blurred Work-Family Boundaries
}

\author{
Scott Schieman and Paul Glavin
}

Version Post-Print/Accepted Manuscript

Citation Schieman, Scott and Paul Glavin. 2016. "The Pressure-Status Nexus

(published version) and Blurred Work-Family Boundaries.” Work and Occupations 43(1):337.

Publisher's Statement The final publication is available at SAGE Publications via https://dx.doi.org/10.1177/0730888415596051.

Always cite the published version, so the author(s) will receive recognition through services that track citation counts, e.g. Scopus. If you need to cite the page number of the TSpace version (original manuscript or accepted manuscript) because you cannot access the published version, then cite the TSpace version in addition to the published version using the permanent URI (handle) found on the record page. 


\title{
The Pressure-Status Nexus and Blurred Work-Family Boundaries
}

\begin{abstract}
Job pressure is associated with increased role-blurring activities. Does higher status attenuate or exacerbate that association? Using data from a national sample of workers, our study discovers that higher status functions as a moderator in what we call the pressure-status nexus. Job pressure is associated more strongly with role blurring among the well-educated, professionals, managers, and high earners. And, job pressure is associated most strongly with role blurring among higher status men. Our articulation of the pressure-status nexus extends the stress of higher status perspective, demonstrating that higher statuses compound the ways that job pressure is linked with activities that blur the work-family boundary.
\end{abstract}

Key words: job pressure, role blurring, work-family interface, status, stress of higher status, gender, border theory, job control 
The idea that work encroaches on the lives of its employees is hardly new. Four decades ago, Lewis Coser (1974) characterized work as a "greedy institution" that has little compunction about extracting time and attention from its workers. As early theorizing about inter-role conflict and role strains foreshadowed (Goode, 1960; Pearlin, 1983), some of this 'greed' is channeled through what has been called work-family role blurring - that is, the integration of behaviors and thoughts associated with work and family roles (Desrochers, Hilton, \& Larwood, 2005; Glavin \& Schieman, 2012). Rapid changes in communication technologies and their increasing use in the workplace have modified employees' accessibility (Bittman, Brown, \& Wajcman, 2009; Valcour $\&$ Hunter, 2005). This has led to greater permeability in the boundaries between work and nonwork life and the integration of these once more separate spheres (Olson-Buchanan and Boswell 2006). Work-family scholars have shown how these changes are due in part to the changing composition of the labor market and, more importantly, the transformation of work itselfespecially the greater prominence of flexible arrangements in the temporal parameters of work (Towers, Duxbury, Higgins, \& Thomas, 2006; MacEachen et al., 2008). Despite this, attempts to systematically document those workplace conditions that are associated with permeability and role blurring are either rare or incomplete (see Glavin \& Schieman, 2012 for an exception). In the present study, we advance on that research by systematically unpacking the multifarious ways in which conditions in high-pressure work contexts are associated with role blurring.

The global economy fuels the demand for flexible schedules and remote work optionsand enhanced communication technologies facilitate the completion of work "anytime, anywhere" (Chesley, 2005). While these technologies often improve personal and organizational functioning, they also generate disruptions outside of work that require border management (Batt \& Valcour, 2003; Kossek \& Lambert, 2005; Hyman, Scholarios \& Baldry, 2005). As the pace, intensity, and complexity of work expands over time (Green, 2005; Kelliher \& Anderson, 2010; 
Maume \& Purcell, 2007), these processes engender a normative intrusion of work contact, via proliferated communication technologies, which leads to an apt contemporary characterization of work as the needy institution. Chesley's (2014) depiction of this trend captures the downsides: "It is possible that the instantaneous nature of technologically facilitated communication and information tasks may be changing social expectations about acceptable response times at work and elsewhere in ways that outstrip the new efficiencies of these innovations" (p. 17). These processes and outcomes bring new challenges to what Moen (2015) calls "work-life quality." Role blurring involves a complex set of interrelated activities that include behavioral indicators (e.g., multitasking on work and family activities; being contacted for work purposes at home) and psychological indicators (e.g., experiencing work-related thoughts while at home) (Voydanoff, 2007). Collectively, these indicators denote high role blurring, since individuals who experience all of them are likely to make less of a distinction between their work and family roles. We expand the scope of prior research by refining a previously developed role blurring measure (see Glavin \& Schieman 2012) in an effort to include a more comprehensive account of the extent that workers send and receive work-related communications outside of regular working hours. Here, we argue that these technologically assisted behaviors represent an important manifestation of role blurring in the contemporary workforce that deserves further assessment (Batt \& Valcour, 2003). It is important to underscore that each of the individual components of role blurring are at once distinctive and yet collectively tap into one underlying theme (described in detail below). A worker might experience frequent work contact and engage in work-family multitasking while at home-but these activities on their own might not fully capture the concept of role blurring. According to Desrochers and Sargent (2004), behaviors and thoughts about work-related matters occur while at home in ways that challenge the separation of work and family domains. Ultimately, its potentially harmful implications for work-family 
conflict encourage analyses of the contexts that contribute to role blurring (Allen, Cho, Meier, 2014; Chesley, 2014; Dex \& Bond, 2005; Voydanoff, 2007).

In the present study, we evaluate the possible influences of one of the most pernicious workplace stressors-job pressure. Glavin and Schieman (2012) established that exposure to job pressures represents a key predictor of role blurring. Our study explicitly extends those findings by evaluating the potential status contingencies in that association. We ask: Does higher statusas measured by education, occupation, job authority, earnings, and job control—modify the association between job pressures and role blurring? We test two competing hypotheses. The status advantage hypothesis predicts that higher status should weaken the positive association between job pressure and role blurring. By contrast, the stress of higher status hypothesis predicts that the positive association between job pressure and role blurring is stronger among those with higher status. In supplemental analyses, we also evaluate if gender functions as an additional contingency in these associations. To test our hypotheses, we analyze data from a national sample of workers — the 2011 Canadian Work, Stress, and Health Study (CANWSH)— which includes individuals across diverse statuses, occupations, sectors, and work conditions.

\section{THEORETICAL FRAMEWORK AND HYPOTHESES}

\section{The Pressure-Status Nexus and Blurred Work-Family Boundaries}

Sociologists have long been interested in the interrelationships among different and sometimes-conflicting social roles (Pearlin, 1983). As the nature of work changes, so too does the particular configuration of those social roles and the competing priorities within them (Jacobs \& Gerson, 2004; Ruppanner \& Huffman, 2014). Moreover, the changing dynamics between roles has spawned a vast body of conceptual language (e.g., "boundary dynamics," "blending," "balance," "fit," and so on) that simultaneously informs theory and analyses (Allen et al., 2014; 
Moen 2015). In Border Theory, which formally articulates the temporal, physical, and psychological characteristics that define the borders between work and non-work roles (Clark, 2000), the concept of permeability is central; it involves the degree to which aspects of one domain are able to enter others (Ashforth et al., 2000). The rapid rise and use of communication technologies generates new challenges for permeability and the integration of work and nonwork domains (Bittman et al., 2009; Chesley et al., 2003). Expanded access to e-mail, laptops, and "smart phone" tools — what Duxbury and colleagues (2006) refer to as "work extending technology" - can enhance flexibility and enable remote work, but these tools also foster permeability that intensifies pressure to accomplish tasks outside traditional workplace parameters (Kelliher \& Anderson, 2010; Matusik \& Mickel, 2011; Valcour \& Hunter, 2005). As Border Theory predicts, these boundary-spanning demands blur the boundaries that separate work and non-work life and require adjustments from workers (Boswell \& Olson-Buchanan, 2007; Chesley, 2014; Kossek \& Lambert, 2005; Voydanoff, 2005). This gives rise to the potentially problematic enactment of role-related activities beyond the usual spatial, temporal, or psychological parameters of work.

We argue that job pressure represents one of the most salient determinants of permeability and, by extension, increases the need for frequent role blurring. Individuals who report job pressure feel overwhelmed by the amount of work they have to do; they have to work on too many tasks at the same time; the demands of their job exceed the time they have to do the work (Diestel \& Schmidt, 2009; Kristensen et al., 2004; Schieman, 2013). Collectively, these pressures and their links to workload, intensification, and overwork increase workers' sense that they must devote additional time to work (Cha \& Weeden, 2014; Chesley, 2014; Duxbury, Lyons, \& Higgins, 2008; Duxbury et al., 2004; Green, 2006; Matusik \& Mickel, 2011; Moen, Lam, Ammons, \& Kelly, 2013). Ultimately, this kind of exploitation — excessively demanding 
work with insufficient time to complete it-requires increased efforts and attention that extend beyond the conventional parameters of the workplace (especially in contexts where "ideal worker" norms are potent). We propose then that, by its very nature, job pressure creates the requirement for permeable work-family borders and an amplification of 'deviant' forms of role enactment. These are the means through which the needy institution ensnares its workers.

Job pressure is highly relevant in work-stress research partly because of its welldocumented pervasiveness in the population. For example, Galinsky and her colleagues (2005) observe that approximately 9 in 10 American workers agree somewhat or strongly that they experience one or more of the following: "my job requires that I work very fast," "my job requires that I work very hard," or "I never have enough time to get everything done on my job." Similarly, approximately one-third of Canadian workers report that they frequently feel overwhelmed by work and that the demands of their job exceed the time to do it; another 40 percent of Canadian workers feel that they are frequently required to work on too many tasks simultaneously (Schieman, 2013). Moreover, the study of job pressure is important given that workers who experience high levels of job pressure tend to encounter more unfavorable personal and social outcomes, including risks to role functioning, health, and well-being (Ducharme \& Martin, 2000; Galinsky, et al., 2005; Glavin et al., 2011; Koltai and Schieman 2015).

The prediction of a positive association between job pressure and role blurring is important in its own right. In fact, there is surprisingly limited research that has documented the association using comprehensive role blurring measures and nationally representative survey data; one exception involves our previous research (Glavin \& Schieman 2012), which found that job pressures were associated with increased role blurring in a national sample of US workers. To our knowledge, however, no studies have subsequently investigated potential contingencies in the relationship between job pressure and role blurring. We propose that association may be 
more complex and multifaceted, and outline theoretical reasons for status as a moderator of this relationship. The question then becomes: What form does such moderation take and is it uniform across various dimensions of status? Below, we articulate our rationale in a process that we call the pressure-status nexus, and the competing hypotheses that emerge from it: the status advantage versus stress of higher status hypotheses. Figure 1 illustrates the main components of this conceptual model.

\section{[INSERT FIGURE 1 ABOUT HERE]}

\section{Status Advantage or Stress of Higher Status?}

While previous research finds that higher status conditions are associated with greater role blurring (Glavin \& Schieman, 2012), we ask: Does higher status modify the relationship between job pressure and role blurring? On the one hand, the status advantage hypothesis predicts that workers with higher status should be better able to withstand the impact of job pressure in ways that minimize role-blurring activities. By contrast, the stress of higher status hypothesis (Schieman, Whitestone, \& Van Gundy, 2006; Schieman, Milkie, \& Glavin, 2009) predicts that job pressure is more strongly coupled with role blurring among workers with higher status. Moen and her colleagues' (2013) show that "work-family stress and time strains driven by conditions at work, especially heavy temporal demands that are no longer bound by space or time" exemplify the experience of professionals (p. 102). Applied here, these ideas imply that professional workers and those with more education, job authority, personal earnings, and job control might experience a weaker relationship between job pressure and role blurring.

Of the two hypotheses, the status advantage view more closely parallels what has been referred to as the 'buffering hypothesis' in the job demands-control (JD-C) and the job demandresources (JD-R) models (Bakker \& Demerouti, 2007; Karasek, 1979; Koltai \& Schieman 2015). In the sociological study of stress, a number of scholars have referenced similar dynamics in 
discussions of coping (Thoits, 1995; Wheaton, 1985), especially with respect to social supportbased resources (Sloan 2012). While those ideas refer to the ways that resources buffer against the distress associated with stressors, we follow Wheaton's (1996) encouragement to evaluate the significance of buffering for the relationships between stressors. Among the forms of status that we assess here, education is the most clearly linked with human capital (Becker, 1964; DiTomaso \& Parks-Yancy, 2014), as well as other forms of job-related resources like selfdirected work (Kohn, 1976; Kohn \& Schooler, 1982; Mirowsky \& Ross, 2003). Ross and Mirowsky (2010) describe education as "a special resource, because it indicates resourcefulness, or the general ability to meet situations effectively" (3). These resource advantages involve the development and deployment of skills, knowledge, cognitive flexibility, and social connections (Mirowsky \& Ross, 2005). From the status advantage perspective, these facets of education should provide tools that help workers minimize the role-blurring activities associated with job pressure. The status advantage hypothesis therefore predicts that education should have the strongest buffering effect in the positive association between job pressure and role blurring.

An alternative perspective - the stress of higher status hypothesis—articulates the possibility that some statuses might exacerbate the positive association between job pressure and role blurring. This view evolves from Blair-Loy's (2009) concept of the "work devotion schema" and the ways that workers who feel greater commitment are likely to expend extra effort and feel more ambition to succeed (Benson \& Brown, 2007). In her qualitative study of "unusually successful women," Blair-Loy (2009) observed that the work devotion ideology might become "purer"-and therefore more consequential—among those with higher status (see pp. 291/307). As Boswell and Olson-Buchanan (2007: 595) observe: "Staying connected after hours may be seen as a means to get ahead in the organization and profession more generally." And Moen and her colleagues (2013) assert that higher status workers might be more receptive to and accepting 
of role blurring. Given ideal worker norms and their implications for expectations about full commitment to work (Acker, 1990; Blair-Loy, 2009; Moen \& Roehling, 2005; Williams, 2000), we propose that the stress of higher status predictions may be particularly pertinent for workers with professional occupational status, greater job authority, and higher earnings. While forms of higher status like job authority are thought to be "highly coveted resources" and aspects of workplace rewards (Smith, 2002:511), greater responsibilities for the direction and content of the work of others may correspond with downsides like role blurring (Schieman \& Reid, 2009).

Regarding the dimensions of job control, Border Theory and the JD-R model both emphasize resources that involve flexibility in the timing and location of work (Bakker \& Geurts, 2004; Voydanoff, 2005). In our analyses, schedule control and job autonomy align with this resource perspective. Schedule control is the degree of control that workers have over the scheduling of their work hours or the capacity to select the times that they start and/or finish work (Golden, 2001), while job autonomy entails the extent that workers have the freedom and responsibility to decide how their work gets done (Kalleberg, 2011). The conventional characterization of schedule control and job autonomy underscores the ways that they should help workers navigate the work-family border (Jacobs \& Gerson, 2004)—as Perlow and Kelly (2014) suggest, these are features of an "accommodation model" in which flexibility is provided by employers to foster employees' management of work demands (see Munsch, Ridgeway, \& Williams, 2014). While there are advantages to these job-related resources, one possible drawback entails greater border permeability and role blurring (Glavin \& Schieman, 2012; Chesley, 2014; Moen et al, 2013; Schieman \& Glavin, 2008). The resource perspective predicts that schedule control and job autonomy should facilitate more efficacious forms of role blending and integration, thereby potentially mitigating the 'interruption' dimensions that make it problematic (Allen et al. 2014). Voydanoff (2005) underscores this point in her account of 
"boundary-spanning resources," asserting that the "flexibility provided by resources such as...work schedule flexibility... reduces work-family conflict and perceived stress by increasing one's ability to perform work activities while also meeting family responsibilities" (p. 492-493). While schedule control and autonomy align more clearly with the typical description of 'resources,' and should therefore attenuate a positive relationship between job pressure and role blurring, another job characteristic—challenging work—presents a more complicated scenario. Challenging work involves activities that require workers to do different things on their job, learn new things, and use their skills and abilities. This concept blends interrelated themes that researchers have labeled with numerous terms like "job enrichment," "task variety," "skill discretion," "self-directed work," "complexity," "non-routine work," and "creative work" (Bakker \& Geurts, 2004; Ford \& Wooldridge, 2012; Hackman \& Oldham, 1976; Karasek, 1979; Mirowsky \& Ross, 2007). While challenging work is a key dimension of job control, it also often reflects higher status in the workplace (DiTomaso \& Parks-Yancy, 2014; Schieman, 2013). From this view, it might function more like other forms of status described above (e.g., job authority) in its potential to exacerbate the positive association between job pressure and role blurring.

In sum, while conventional thinking tends to favor the status advantage hypothesis prediction that higher status should weaken the association between job pressures and role blurring, the stress of higher status hypothesis provides an alternative: Higher status might strengthen the positive association between job pressure and role blurring —or, fail to attenuate it. Moreover, different forms of job control also yield competing predictions about attenuation versus exacerbation of the expected positive association between job pressure and role blurring.

\section{Gender and the Pressure-Status Nexus}


Adding to the complex moderating scenarios described above, it is also possible that the interrelationships articulated in the pressure-status nexus and our two competing hypotheses differ for women and men. Previous efforts to investigate potential gender differences in role blurring have been hampered by a dearth of studies that utilize nationally representative samples of workers. The limited available evidence, however, does suggest that men report more role blurring than women, and that job resources that entail control over the nature and timing of work are more predictive of greater role blurring among men (Glavin \& Schieman, 2012; Schieman \& Glavin, 2008; Voydanoff, 2005). However, research that identifies gender differences in the interrelationships between job pressures and role blurring is generally lacking.

The theoretical basis for anticipating gender differences in our focal hypotheses revolves around the long-standing articulation of the gendered nature of work and the work-family border (Damaske, Ecklund, Lincoln, \& White, 2014; Yaish \& Stier 2009). In particular, this provides a gendered view of border theory and its description of permeability in ways that help elaborate on the hypotheses described above. The broad claim is that women and men tend to experience the work-family interface differently (Winslow, 2005); in this regard, different socio-cultural orientations shape the realities of permeability and, by extension, the extent and forms of roleblurring activities. From a traditional view of gender roles, the meanings, values, and obligations might continue to differ for women and men. Decades ago, Pleck (1977) proposed that because women have traditionally prioritized family over work, they might be less likely to experience interference from work into the home. By contrast, the traditional notion that men should be "good providers" for their family implies that they might be more likely to prioritize work and, when required, allow work matters into the household (Duxbury \& Higgins, 1991; Pleck, 1985).

This gendered model of the ideal worker involves an unequal weighting of family versus work priorities such that the needs of work are favored (Acker, 1990; Davies \& Frink, (2014; 
Kanter, 1977; Williams, 2000). In this regard, men who engage in work-family role blurringespecially in the context of high job pressures-reinforce the masculine stereotype. This is not to suggest that the family is less important for men, but rather that the work role is highly salient and therefore, when work calls, men should answer. These claims have direct implications for the pressure-status nexus: Some indicators of higher status position—especially professional occupational status, greater job authority, and higher earnings - might more strongly exacerbate the relationship between job pressure and role blurring among men. In high-pressure contexts, ideal worker norms might intensify. It is therefore plausible that, among men, higher status work increasingly requires them to blur boundaries - with amplified expectations to take work home in ways that both reflect and the subsequently increase the permeability of the work-family border.

A parallel but somewhat different argument describes the ways that men are increasingly contributing time and energy to the non-economic aspects of fatherhood, and in this regard have perceived themselves as 'central participants' in activities in the home sphere (Barnett \& Rivers, 1996; Coltrane, 1996; Gerson, 1993; Grzywacz \& Marks, 2000; Townsend, 2002). If men have become less likely to define home-related role activities as supplemental to their work role, then they might also experience the greatest need for role blurring — especially when they are situated in the pressure-status nexus. By contrast, when higher status women experience similarly high levels of job pressure, the manner in which this relates to permeability — and ultimately, role blurring - might be more constricted. In the context of cultural norms and values associated with being a 'good mother,' women might attempt to keep work and family roles more segmented and therefore limit role blurring. Interpreting these ideas in the framework of our hypotheses implies that the stress of higher status hypothesis might more accurately characterize the experience of men. Analytically, this requires a three-way interaction test to evaluate if the job pressure $x$ 
status interactions for women and men - that is, whether or not the pressure-status nexus is a gendered experience that yields divergent consequences for work-family role blurring.

\section{METHODS}

Sample

To test our hypotheses, we use data from the 2011 Canadian Work Stress and Health study (CANWSH), a national sample of Canadian workers. Interviews were conducted by telephone between January and July 2011; we hired the survey organization R.A. Malatest to recruit the sample and conduct the interviews. To be eligible, individuals had to be: (1) residing in Canada; (2) at least 18 years of age; (3) currently in a paid job or operating an incomeproducing business; (4) employed in the civilian labour force; and 5) living in a non-institutional residence. In households with more than one eligible person, the "next birthday" method was used to randomly select a participant. Calls were made to a regionally stratified unclustered random probability sample generated by random-digit-dial methods. Interviews were conducted in English or French and averaged 35 minutes. A \$20 gift card was offered as incentive. The full sample was 6,004 , with a response rate of approximately 40 percent. ${ }^{1}$ We obtained a final analytical sample of 4,527 cases after excluding the self-employed, those working fewer than 20

\footnotetext{
${ }^{1}$ While a higher response rate is the ideal - and we expended great efforts to achieve one- this has become increasingly challenging for all survey researchers (with limited budgets). There are conflicting views on the meanings and implications of a 'low' response rate. Nonresponse bias in estimates is one concern (Babbie, 2010), although research challenges the link between response rates and nonresponse bias (see Groves, Crouper \& Presser, 2007; Curtin, Presser \& Singer, 2000; Merkle \& Edelman, 2002). To address the possibility that our results were unduly influenced by nonresponse bias, we compared unweighted and weighted analyses in which we weighted the sample based on a key demographic statuses (e.g. gender, age, marital status, education) from the most recent Canadian Census. We found few differences between the weighted and unweighted results. Winship and Radbill (1994) argue that controlling for characteristics on which individuals may be under-sampled or over-sampled helps adjust for biases due to these characteristics. Given that all of our analyses include these controls, nonresponse bias should not be a major problem for the estimates reported here. As an additional comparison, the CANWSH response rate of 40 percent falls in the range of three similar studies: (1) The 2008 National Study of the Changing Workforce achieved 55 percent (Families and Work Institute); (2) The 2004 National Study of Overwork in America achieved a 23 percent response rate (Galinsky et al., 2005); and (3) in the 2001 National Work-Life Conflict Study of Canadian workers, the study authors report a response rate of approximately 26 percent (Higgins \& Duxbury, 2002).
} 
hours per week, those with missing values on the dependent variable, and after weighting the data in accordance with the gender, age, education, and marital status composition of the Canadian workforce.

\section{MEASURES}

\section{Work-Family Role Blurring}

We developed a new five-item index that assesses frequency of role blurring activities. This index builds on our previous three-item measure that examined the frequency that workers are contacted about work-related matters outside of normal work hours, engage in work-family multitasking, and have work-related thoughts outside of the workplace (Glavin and Schieman 2012). As part of the current index, participants were asked: (1) "How often were you called about work-related matters when you were not at work?” (2) “How often did you read jobrelated email or text messages when you were not at work?" (3) "How often did you contact people about work-related matters when you were not at work?" (4) "How often do you try to work on job tasks and home tasks at the same time while you are at home?" and (5) "How often did you think about work-related things when you were not working?" This index builds upon the previous index by assessing the reciprocal nature of both receiving and sending work-related communications. The two new items (3 and 4) extend the conceptual scope of the index by including the respondents' initiation of role blurring — rather than simply the passive receipt of after-hours contact - and therefore taps the exchange element of these dynamics. Using the past three months as the orienting time frame, we provided these response choices: "never" (coded 1), "rarely" (2), "sometimes" (3), “often" (4), and "very often" (5). Factor analysis (not shown) confirms the items tap one underlying construct and the scale has good reliability $(\alpha=.80)$. We averaged the responses to the five items to create the work-family role-blurring index. 


\section{Job Pressure}

We use three items to measure job pressure that are similar to those used in other previously published research on similar themes like "workload" or "quantitative demands" (Kristensen et al., 2004; Van den Broek, Vansteenkiste, De Witte, \& Lens, 2008). The items ask about the following experiences in the past 3 months: "How often did you feel overwhelmed by how much you had to do at work?" "How often did you have to work on too many tasks at the same time?" "How often did the demands of your job exceeded the time you have to do the work?" Response choices are: "never" (1), "rarely" (2), "sometimes" (3), "often" (4), and "very often" (5). Responses are averaged, with higher scores indicating more job pressure $(\alpha=.85)$.

\section{Statuses}

Education. We coded educational attainment as follows: (1) "less than high school," (2) "high school or GED," (3) “associate/2-year degree," (4) “some college, no degree earned," (5) "4-year university degree," and (6) "graduate or professional degree."

Professional occupation. To assess occupation, we asked: "What kind of work do you do? That is, what is your occupation?" Using the open-ended information provided, occupations are coded into thirty-three categories using the 2006 Canadian National Occupation Classification. We compare individuals in professional or executive occupations with a category that combines all others (technical, service, sales, administrative and production).

Job authority. Responses to three items are used to assess job authority: "Do you supervise or manage anyone as part of your job?" "Do you influence or set the rate of pay received by others?"; "Do you have the authority to hire or fire others?" Workers with no authority are compared to workers with supervisory or managerial authority (Elliott \& Smith, 2004; Schieman, Schafer, \& McIvor, 2013; Smith, 2012). Individuals who responded "no" to all 
three items are classified as having no authority (the reference group). Participants who responded "yes" only to the "supervise or manage" item are classified as having supervisory authority. Those who supervise others and have some degree of sanctioning authority — that is, they set pay or can hire/fire others - are classified as having managerial authority.

Personal income. One item is used to measure personal income. It assesses total personal earnings in the previous year from all sources. We coded income into quartiles.

Job autonomy. Three items are used to assess job autonomy. Participants are asked the extent that they agree or disagree with the following statements: "I have the freedom to decide what I do on my job," "It is basically my own responsibility to decide how my job gets done," and "I have a lot of say about what happens on my job." Response choices are coded "strongly disagree" (1), "somewhat disagree" (2), "somewhat agree" (3), and "strongly agree" (4). Responses are averaged; higher scores reflect more job autonomy $(\alpha=.76)$.

Schedule control. One item asks: "Who usually decides when you start and finish work each day?" The "someone else" response choice is coded 1, "you are able to decide within limits" is coded 2, and "you are entirely free to decide" is coded 3.

Challenging work. Five items measure challenging work: "My job requires that I keep learning new things," "My job requires that I be creative," "My job lets me use my skills and abilities," "The work I do on my job is meaningful to me," and "I get to do a lot of different things on my job." Response choices are: "strongly disagree” (1), "somewhat disagree” (2), "somewhat agree" (3), and "strongly agree" (4). Responses are averaged, with higher scores reflecting more challenging work $(\alpha=.79) .^{2}$

\footnotetext{
2 The correlations among the focal continuous measures are as follows: job autonomy and challenging work $(\mathrm{r}=.44$, $\mathrm{p}<.001)$; job autonomy and job pressure $(\mathrm{r}=-.05, \mathrm{p}<.001)$; challenging work and job pressure $(\mathrm{r}=.10, \mathrm{p}<.001)$.
} 


\section{Control Variables}

Gender is coded 0 for men and 1 for women. Participants' age is coded in years. Married is coded 1 for married and 0 for all others. Those with children at home are coded 1 and 0 for all others. Private sector jobs are coded 1 and all others are coded 0. Work hours compare part-time (fewer than 35 hours) with those who report full-time (35 to 49 hours) or overwork (50-plus). All analyses adjust for region (e.g., Ontario versus British Columbia, Quebec, Alberta, and so on).

\section{Plan of Analyses}

Ordinary least squares (OLS) regression techniques are used to test models. In Model 1 of Table 1, role blurring is regressed on job pressure, statuses, and control variables. Subsequent models test for interaction terms for job pressure $\times$ education (model 2), professional status (model 3), job authority (model 4), income (model 5), job autonomy (model 6), and schedule control (model 7). Only the job pressure $\times$ challenging work coefficient was statistically insignificant and is therefore not reported in the table. In supplemental analyses to evaluate gender contingencies among the two-way interactions, we tested three-way interaction terms; this involved creating job pressure $\times$ status $\times$ gender terms. For the sake of presentation, however, in Table 2 we only report the three statistically significant three-way interactions. The Appendix table provides basic descriptive statistics of study variables for women and men.

\section{RESULTS}

\section{The Pressure-Status Nexus}

The results in model 1 of Table 1 indicate that job pressure is associated strongly and positively with role blurring. In addition, those with more education, professional status, supervisory or managerial status, schedule control, and challenging work report more frequent 
role blurring; importantly, each of those effects holds net of all the others. These patterns are consistent with previous research examining the work-related antecedents of role blurring (Glavin \& Schieman, 2012). For income, the patterns are non-linear: Only those in the highest earning quartile report significantly more role blurring compared to the lowest earners (the reference group). For job autonomy, the quadratic term indicates that the association between autonomy and role blurring is flat up to a point beyond which, at higher levels of autonomy, the relationship between autonomy and role blurring becomes increasingly stronger. Among the control measures we observe that men, younger workers, and those with children at home report more frequent role blurring. Collectively, these patterns indicate that work-family role blurring is unequally distributed in the population of Canadian workers - and clearly demonstrates that workers with higher levels of status tend to experience significantly more of it.

\section{[INSERT TABLE 1 ABOUT HERE]}

Turning to the interaction coefficients, models 2 and 3, respectively, demonstrate that the association between job pressure and role blurring is significantly more positive among those with higher levels of education and professional status $(\mathrm{p}<.001)$. While job pressure is strongly related to role blurring, these interactions suggest that higher education and professional status do not buffer the impact of job pressure on role blurring - patterns that are contrary to the status advantage hypothesis predictions. Instead, these findings are more consistent with the stress of higher status hypothesis. Figure 2 illustrates the results for the education-based contingency.

\section{[INSERT FIGURE 2 ABOUT HERE]}

In model 4 , the statistically significant pressure $\times$ manager interaction coefficient indicates that the positive relationship between job pressure and role blurring is stronger among managers compared to workers with no job authority $(\mathrm{p}<.001)$. Importantly, however, having only supervisory status does not moderate the pressure-role blurring association-this represents 
an important distinction between supervisory versus managerial authority, with the latter reflecting higher levels of control over organizational resources and, by extension, greater status. Likewise, as model 5 demonstrates, job pressure is also more strongly associated with elevated role blurring among workers in the highest income quartile $(\mathrm{p}<.001)$. Taken together, these two core dimensions of socioeconomic status and positional location in the workplace amplify rather than attenuate the positive association between job pressure and role blurring — and, like education and professional status, are consistent with the stress of higher status hypothesis.

The significant job pressure $\times$ job autonom $y^{2}$ coefficient (model 6) suggests that the moderating effect of autonomy is non-linear. The positive association between job pressures and role blurring is strongest among those with low levels of autonomy. Put differently, the gap in role blurring is widest among individuals with lower levels of job pressure, and that gap diminishes at an accelerated rate as levels of pressure increase-with a steeper slope observed for those with low job autonomy. Similarly, the job pressure $\times$ some schedule control interaction coefficient (model 7) indicates that pressure is more strongly associated with role blurring among workers who have some schedule control (compared to those with no schedule control). By comparison, however, having full schedule control does not moderate the association.

\section{Gender and the Pressure-Status Nexus}

In supplemental analyses, we tested whether any of the statistically significant two-way interactions that we reported in Table 1 are further contingent upon gender - that is, do the observed stress of higher status effects differ for women and men? As Table 2 indicates, only the three-way terms involving professional status, managerial status, and income are statistically significant. That is, job pressure is more strongly associated with work-family role blurring among professionals, managers, and high earners—-but in each case, those patterns are more 
representative of men's experience. Figures 3, 4, and 5 show each of those findings. Collectively, these results demonstrate that the stress of higher status hypothesis - as represented in the pressure-status nexus - more accurately reflects the experience of men compared to women.

[INSERT TABLE 2 AND FIGURES 3 - 5 ABOUT HERE]

\section{DISCUSSION}

Feeling overwhelmed by the amount of work one has to complete and the squeeze of excessive tasks and insufficient time represent quintessential forms of exploitation experienced by the modern-day worker. These kinds of job pressures are important to study because of their negative consequences for workers' performance and well-being; however, in this paper we consider an additional possibility in the study of job pressure - the proclivity for workplace demands to facilitate increased permeability of the work-family border and role blurring. This element of the work-life boundary dynamic generates the potential for 'deviant' forms of role enactment and provides a basis for unexpected patterns of emotional inequality. Confirming previous observations among Americans (Glavin \& Schieman, 2012), and expanding upon an earlier role blurring measure, here we demonstrate a strong positive association between job pressure and the frequency of work-family role-blurring activities in a large national sample of Canadian workers. In addition, two other discoveries make novel contributions beyond that previous study. First, we document that each form of status — education, professional status, job authority, and income — are related positively and independently to more frequent role blurring. These patterns lend additional empirical support for the stress of higher status thesis (Glavin \& Schieman, 2012; Schieman et al. 2009). Second, we examine the ways that job pressures relate to role blurring across lower, moderate, and higher statuses; the relationship between job pressure and role blurring does indeed vary considerably across these different levels of status. 
The set of particular combinations of job pressure and status - what we call the pressurestatus nexus - are among the most compelling findings in our analyses. Specifically, we demonstrate that job pressure is more strongly associated with frequent role blurring among individuals with higher education, professional status, managerial authority, and higher earnings. Moreover, these patterns hold steady even after we account for three forms of job control or jobrelated resources: schedule control, job autonomy, and challenging work. And, importantly, the results also remain net of adjustments for the extent of overwork - that is, the commonlydocumented experience of working longer hours among those with higher status (Cha \& Weeden, 2014). Taken together, we interpret these findings as being consistent with the stress of higher status hypothesis. The fact that individuals embedded in higher status conditions experience a significantly stronger coupling of job pressure and role blurring directly contradicts the status advantage hypothesis and its prediction that higher statuses should attenuate the positive relationship between job pressure and work-family role blurring.

The relevance of these findings extend beyond the narrow parameters of the work-family border by intersecting with broader debates about ideal worker norms and their consequences for worker functioning, particularly across levels of socioeconomic standing (Correll, Kelly, O’Connor, and Williams, 2014). Higher status workers might experience a greater devotion or commitment to their jobs and therefore are more willing — and possible often expected — to allow work-related tasks to spillover outside conventional parameters. Role blurring may simply be an implicit (or even explicit) part of the job description for today's higher status workers; the greater dedication implies an acceptance of the price of ambition-one that involves blurred work-family boundaries (Benson \& Brown, 2007; Blair-Loy, 2003). However, it is worth underscoring here that we are not simply describing the conditions of higher status workers, but rather elaborating on their potential role enactments and dynamics in high-pressured contexts. 
Another way to view our results is to imagine that if we randomly selected any two individuals in our sample who experience higher levels of job pressure, the worker with the higher status is more likely to engage in frequent role blurring. This kind of role blurring might be the 'new normal' because of greater ambition, or because higher status workers-when under more intense time pressure and role overload — might feel more compelled to blur the boundaries of work and non-work life to "get ahead" or maintain their higher status (Moen et al., 2013). But, to be clear, these patterns do not imply that the job pressures experienced by lower status workers are somehow less painful or detrimental. Rather, lower status workers might be less likely to have the kind of content or demands in their work activities that foster role-blurring activities, or their experience of pressure might be more constrained to the particular spatial and temporal parameters of the workplace. While high job pressures might manifest in other negative outcomes for lower status workers (e.g., conflict, poorer health, dissatisfaction), it might manifest less directly in the stress associated with role blurring. Certainly, though, much more research — both qualitative and quantitative — is needed to understand the complex link between job pressure and role blurring across the entire socioeconomic and occupational spectrum.

In addition to the basic patterns of the pressure-status nexus, we expand upon prior findings by demonstrating three gender-contingent patterns. Consistent with our previous observations (Glavin and Schieman 2012), we first confirm that men report more frequent role blurring than women; yet, it is the gendered nature of the relationship between job pressures and role blurring that is especially novel. Job pressure is more strongly associated with frequent role blurring among professionals, managers, and higher earners — and those relationships are more apparent among men compared to women. These findings reinforce the notion of a gendered model of the ideal worker norm in which women and men experience a different weighting of work- versus family-related expectations and responsibilities. At least in this form of pressure- 
status nexus, there is evidence that men tend to be more likely to blur the borders between work and family.

Our findings in no way imply that higher status women in high-pressured job contexts are not also engaging in frequent work-family role-blurring activities. In fact, one finding stands out: Job pressure is the strongest predictor of role blurring among both women and men-especially those with higher status. However, it is the relative comparison between men and women that reveals the additional gender gap that reinforces the masculine stereotype. It may be that the nature of the work or the type of job differs for women and men in such a way that when work contact occurs, for example, men are more likely to feel that they should respond. There is some suggestion in prior research that men with job authority report a wider span of responsibility at work. According to Wright and colleagues (1995), "because of the real power associated with positions in authority hierarchies, gender inequalities in authority may constitute one of the key mechanisms that sustain gender inequalities in workplace outcomes" (p. 407). Marsden and colleagues (1993) suggest that women have also tended to hold jobs with fewer "commitmentenhancing features" (e.g., supervisory positions), but even when women hold similar positions of job authority as men, there is some indication that the scope of their authority is more narrow. Prior research also suggests that women tend to cluster in positions of more circumscribed authority, in which they have a narrower band of responsibilities for overseeing other workers with fewer of the other benefits typically associated with authority (Reskin \& Ross, 1992). Collectively, these ideas imply that women in managerial positions might therefore be better able to maintain less permeable borders - even in high-pressured contexts. While ideal worker norms are influential, higher status men might also feel norms regarding the ideal father, and therefore desire to contribute more time and energy to the non-economic aspects of fatherhood (Barnett \& Rivers, 1996; Coltrane, 1996; Gerson, 1993; Grzywacz \& Marks, 2000; Townsend, 2002). 
Future research could benefit from a deeper exploration of ideal worker norms and their influence on the gendered experiences of the pressure-status nexus.

As for the three job-related resources — schedule control, autonomy, and challenging work - each one is associated with more frequent role blurring. This point is worth underscoring: These job resources are each independently related to greater exposure to a potential stressor. Moreover, only schedule control and autonomy modify the effect of job pressure - and those patterns are not linear. For schedule control, the positive relationship between job pressure and role blurring is stronger among those with some schedule control (compared to none). Taken together, these patterns have implications for notions of 'flexibility' and 'resources' in both Border Theory and the JD-R model, and their predictions about role blurring (Bakker \& Geurts, 2004; Voydanoff, 2005). In particular, the conventional characterization of schedule control and job autonomy underscores the ways that they should enable workers to navigate the work-family border (Jacobs \& Gerson, 2004). If that were true, it could be argued that these would also help attenuate the positive link between job pressure and role blurring. For workers with some schedule control, however, that relationship is actually stronger (not weaker, as the status advantage hypothesis predicted). Why does having only some schedule control seem to amplify the blurred boundaries that come with pressure? It may be that individuals with some schedule control have more opportunities than those with no schedule control to engage in role blurringthat is, they can choose their own start and end times (within limits). In this context, 'work creep' might be more problematic compared to those with a more rigid schedule. Flexibility might come with expectations that work can be done elsewhere, at other times. This is another salient feature of the stress of higher status that connects to ideal worker norms and work devotion. 


\section{CONCLUSION}

While it is possible that role blurring may be functional or even desirable - a means to reducing commuting costs, for example — it is worth noting that previous research has shown a positive association between role blurring at home and work-family conflict (Glavin \& Schieman 2012; Voydanoff 2005). Indeed, for some workers, role blurring may initially begin as part of an attempt to deal with excessive job pressures and reduce inter-role conflict; paradoxically, however, these behaviors might expand the reach of work demands into non-work domains in ways that normalize rather than ameliorate these pressures. Future research should test these possibilities by exploring the temporal pathways that connect job pressures, role blurring and work-family conflict. It is also worth investigating the temporal dimensions among these relationships: Is the link between job pressures and role blurring unidirectional? Or is it possible that role blurring contributes to increased perceptions of pressures that produce an upward spiral of overwork? Does role blurring facilitate the ways that work intensification generates inter-role conflict—and do higher status work conditions engender such processes? Much remains unknown about the ways that these dynamics unfold over time for workers across statuses.

Our study also contributes to the ongoing debate and discussion about the concept of role blurring itself. The earlier work of Desrochers and colleagues (2005), in which they identified the "Work-Family Integration-Blurring Scale" (WFIBS), provides a foundational framework. They conceptualized work-family role blurring as "as the experience of difficulty in distinguishing one's work from one's family roles" (p. 460). The WFIBS is a three item index consisting of the following: (1) "It is often difficult to tell where my work life ends and my family life begins"; (2) "I tend to integrate my work and family duties when I work at home"; (3) and "In my life, there is a clear boundary between my career and my role as a parent." By comparison, our conceptualization and operationalization of role blurring is more oriented 
towards specific activities, especially related to after-hours work contact and multitasking. We view our measure as a possible determinant of the WFIBS - that is, for example, people who frequently send and receive work-related communications after hours should be more likely to (subsequently) have difficulties figuring out where work life ends and family life begins or experience a lack of clarity in the boundary between one's career versus parenting.

Beyond questions about overlap with the WFIBS, a recent piece by Allen and colleagues (2014) further contends that some of the items in our earlier measure (see Glavin and Schieman 2012) "are similar to items used to capture interruptions as well as a lack of psychological detachment from work" (p. 109). Allen and colleagues raise important questions about the distinctions between and/or interrelationships among different constructs. We agree that these lines can seem somewhat blurry. In our view, however, "distractions," "interruptions," or the "inability to detach from work" are potential consequences of role blurring-but they are not necessarily the same as role blurring activities. For example, Desrochers and colleagues (2005) measure disruptions with a single item: "When I work at home, distractions often make it difficult to attend to my work" (p. 453). Here, there is a clear conceptual distinction between role blurring and its consequences (e.g., distraction/interruption), but once again there is the suggestion of an empirical relationship between them. For example, workers who frequently send emails after work hours might subsequently experience interruptions or remain "cognitively preoccupied" with their work well beyond the normal temporal parameters of work. We submit that these are empirical questions that require tests of the relationships among different constructs: When do role-blurring activities, such as the sending and receiving of work-related communications or work-family multitasking, create disruptions or interruptions at home? Do role-blurring activities automatically result in workers having difficulties psychologically disengaging with work? This is fertile terrain for future research. 
We also think it might be unwise to assume that role blurring necessarily equates to work detachment problems. Some might characterize detachment from work as a 'natural' (and desirable) state, but there are a number of vocational callings where there is little clear distinction between work and non-work roles (e.g. the clergy, on-duty soldiers, and perhaps even some politicians). For these individuals, the blurring of roles should not automatically represent a failure to detach from work, but it might simply be the way they experience the work-family interface, integration versus segmentation, and their own various role identities. Thus, individuals might experience role blurring that is not necessarily indicative of work detachment problems. Certainly, in many cases, role blurring could be a strong predictor of detachment problems - but this is yet another question that deserves greater scrutiny in future research.

Finally, it is essential to acknowledge that the pressure-status nexus occurs within what Moen (2015) has recently referred to as the "institutional/organizational turn," that is, a consideration of the structural constraints placed around micro-/individual-level processes. While our account is admittedly individual-focused, we recognize that the pressure-status nexus occurs within broader institutional/organizational contexts that shape work-life boundary dynamics. The workplace culture might shape the degree to which the pressure-status nexus facilitates role blurring. For instance, some organizational cultures might simply expect frequent work contact outside of regular working hours, while other organizations endeavor to restrain the greedy impulse of after hours contact. The former encourages more frequent deviant role enactments, while the latter discourages it. Unfortunately, we do not have measures that might help account for any influence that organizational culture, but future inquiry might consider it. This could illuminate the point at which the 'potential stressor' of role blurring becomes what Wheaton (1996) calls a 'stressful stressor' — one that actually has an impact on health and well-being. 
REFERENCES

Acker, J. (1990). Hierarchies, jobs, bodies: A theory of gendered organizations. Gender \& Society, 4(2), 139-158.

Allen, T. D., Cho, E., \& Meier, L. L. (2014). Work-family boundary dynamics. Annual Review of Organizational Psychology and Organizational Behavior, 1, 99-121.

Ashforth, B. E., Kreiner, G. E., \& Fugate, M. (2000). All in a day's work: Boundaries and micro role transitions. Academy of Management Review, 25(3), 472-491.

Babbie, E. (2010). The practice of social research. Belmont, CA, US: Wadsworth Cengage Learning.

Bakker, A. B., \& Geurts, S. A. E. (2004). Toward a dual-process model of work-home interference. Work and Occupations, 31, 345-366.

Bakker, A. B., \& Demerouti, E. (2007). The Job-demands-resources model: State of the art. Journal of Managerial Psychology, 22, 309-328.

Barnett, R. C., \& Rivers, C. (1996). She works, he works: How two-income families are healthier and better off. San Francisco: Harper.

Batt, R., \& Valcour, M. (2003). Human resource practices as predictors of work/family outcomes and employee turnover. Industrial Relations, 42, 189-220.

Becker, G. S. (1964). Human capital theory. Chicago, University of Chicago Press.

Benson, J., \& Brown, M. (2007). Knowledge workers: what keeps them committed; what turns them away. Work, Employment \& Society, 21(1), 121-141.

Blair-Loy, M. (2009). Competing devotions: Career and family among women executives. Harvard University Press.

Bittman, M., Brown, J. E., \& Wajcman, J. (2009). The mobile phone, perpetual contact and time pressure. Work, Employment \& Society, 23(4), 673-691. 
Boswell, W. R., \& Olson-Buchanan, J. B. (2007). The use of communication technologies after hours: The role of work attitudes and work-life conflict. Journal of Management, 33(4), 592-610.

Cha, Y., \& Weeden, K. A. (2014). Overwork and the slow convergence in the gender gap in wages. American Sociological Review, 79(3), 457-484.

Chesley, N. (2014). Information and communication technology use, work intensification and employee strain and distress. Work, Employment \& Society, 67, 1237-48

Chesley, N. (2005). Blurring boundaries? Linking technology use, spillover, individual distress, and family satisfaction. Journal of Marriage and the Family, 67, 1237-1248.

Chesley, N., Moen, P., \& Shore, R. P. (2003). The new technology climate. In P. Moen (Ed.), It's about time: Couples and careers (pp. 220-241). Ithaca, NY: Cornell University Press.

Clark, S. C. (2000). Work/family border theory: A new theory of work/family balance. Human Relations, 53, 747-770.

Coltrane, S. (1996). Family man. New York: Oxford University Press

Correll, S. J., Kelly, E. L., O’Connor, L. T., \& Williams, J. C. (2014). Redesigning, redefining work. Work and Occupations, 41(1), 3-17.

Coser, L. (1974). Greedy institutions. New York, NY: Free Press.

Curtin, R., Presser, S., \& Singer, E. (2005). Changes in telephone survey nonresponse over the past quarter century. Public opinion quarterly, 69(1), 87-98.

Davies, A. R., \& Frink, B. D. (2014). The origins of the ideal worker: the separation of work and home in the United States from the Market Revolution to 1950. Work and Occupations, 41(1), 18-39. 
Damaske, S., Ecklund, E. H., Lincoln, A. E., \& White, V. J. (2014). Male scientists' competing devotions to work and family: changing norms in a male-dominated profession. Work and Occupations, 41(4), 477-507.

Desrochers, S., \& Sargent, L. D. (2004). Boundary/border theory and work-family integration. Organization Management Journal, 1, 40-48.

Desrochers, S., Hilton, J. M., \& Larwood, L. (2005). Preliminary validation of the work-family integration-blurring scale. Journal of Family Issues, 26, 442-466.

Dex, S., \& Bond, S. (2005). Measuring work-life balance and its covariates. Work, Employment \& Society, 19(3), 627-637.

Diestel, S., \& Schmidt, K. H. (2009). Mediator and moderator effects of demands on self-control in the relationship between work load and indicators of job strain. Work \& Stress, 23(1), 60-79.

DiTomaso, N., \& Parks-Yancy, R. (2014). The social psychology of inequality at work: individual, group, and organizational dimensions. In J. D. McLeod (Ed.), Handbook of the Social Psychology of Inequality (pp. 437-457). Springer Netherlands.

Ducharme, L. J., \& Martin, J. K. (2000). Unrewarding work, coworker support, and job satisfaction a test of the Buffering Hypothesis. Work and Occupations, 27(2), 223-243.

Duxbury, L., Lyons, S., \& Higgins, C. (2008). Too much to do, and not enough time: An examination of role overload. In K. Korabik, D. S. Lero, and D. L. Whitehead (Eds.), Handbook of Work-Family Integration: Research, Theory, and Best Practices (pp. 12540). London, UK: Academic Press/Elsevier.

Duxbury, L. E., \& Higgins, C. A. (2002). The 2001 national work-life conflict study: Report one. Ottawa: Health Canada. 
Duxbury, L. E., Thomas, J. A., Towers, I., \& Higgins, C. (2004). From 9 to 5 to 24 and 7: How technology has redefined the workday. In W. Law (Ed.) Information resources management: Global challenges (pp. 305-32). Hershey: Idea Group Publishing.

Duxbury, L. E., \& Higgins, C. A. (1991). Gender differences in work-family conflict. Journal of Applied Psychology, 76(1), 60-74.

Elliott, J. R., \& Smith, R. A. (2004). Race, gender, and workplace power. American Sociological Review, 69(3), 365-386.

Ford, M. T., \& Wooldridge, J. D. (2012). Industry growth, work role characteristics, and job satisfaction: a cross-level mediation model. Journal of Occupational Health Psychology, $17(4), 492-504$.

Galinsky, E., Bond, J. T., Kim, S. S., Backon, L., Brownfield, E., \& Sakai, K. (2005). Overwork in America: When the way we work becomes too much, executive summary. New York: Families and Work Institute.

Gerson, K. (1993). No man's land: Men's changing commitments to family and work. New York Basic Books.

Golden, L. (2001). Flexible work schedules: What are workers trading off to get them? Monthly Labor Review, 124, 50-67.

Green, F. (2006). Demanding work: The paradox of job quality in the affluent economy. Princeton University Press.

Groves, R., Couper, M., \& Presser, S. (2007). Experiments in producing nonresponse bias. Peace Research Abstracts Journal, 44(3), 720-736. 
Glavin, P., \& Schieman, S. (2012). Work-family role blurring and work-family conflict: The moderating influence of job resources and job demands. Work and Occupations, 39, 7198.

Glavin, P., Schieman, S., \& Reid, S. (2011). Boundary-spanning work demands and their consequences for guilt and psychological distress. Journal of Health and Social Behavior, $52(1), 43-57$.

Goode, W. J. (1960). A theory of role strain. American Sociological Review, 25(4), 483-496.

Grzywacz, J. G., \& Marks, N. F. (2000). Reconceptualizing the work-family interface: An ecological perspective on the correlates of positive and negative spill- over between work and family. Journal of Occupational Health Psychology, 5, 111-126.

Hackman, J. R., \& Oldham, G. (1976). Motivation through the design of work: Test of a theory. Organizational Behavior \& Human Performance, 16, 250-279.

Hyman, J., Scholarios, D., \& Baldry, C. (2005). Getting on or getting by? Employee flexibility and coping strategies for home and work. Work, Employment \& Society, 19(4), 705-725

Jacobs, J. A., \& Gerson, K. (2004). The time divide: Work family and gender inequality. Cambridge, UK: Harvard University Press.

Kalleberg, A. L. (2011). Good jobs, bad jobs: The rise of polarized and precarious employment systems in the United States, 1970s-2000s. Russell Sage Foundation.

Kanter, R. M. (1977). Men and Women of the Corporation. New York. Basic books.

Karasek, R. (1979). Job demands, job decision latitude, and mental strain: Implications for job redesign. Administrative Science Quarterly, 24, 285-306.

Kelliher, C., \& Anderson, D. (2009). Doing more with less? Flexible working practices and the intensification of work. Human Relations 63(1): 83-106. 
Kohn, M. L. (1976). Occupational structure and alienation. American Journal of Sociology, 82, 111-130.

Kohn, M. L., \& Schooler, C. (1982). Job conditions and personality: A longitudinal assessment of their reciprocal effects. American Journal of Sociology, 87, 1257-1286.

Koltai, J., \& Schieman, S. (2015). Job pressure and SES-contingent buffering: Resource reinforcement, substitution, or stress of higher status? Journal of Health and Social Behavior, 1-19. DOI: 10.1177/0022146515584151.

Kossek, E., \& Lambert, S. J. (2005). Work-family scholarship: voice and context. In E. E. Kossek \& S. J. Lambert (Eds.) Work and life integration: Organizational, cultural, and individual perspectives, (pp. 3 -17). Mahwah, NJ: Lawrence Erlbaum Associates.

Kristensen, T. S., Bjorner, J. B., Christensen, K. B., \& Borg, V. (2004). The distinction between work pace and working hours in the measurement of quantitative demands at work. Work \& Stress, 18(4), 305-322.

MacEachen, E., Polzer, J., \& Clarke, J. (2008). "You are free to set your own hours": Governing worker productivity and health through flexibility and resilience. Social Science \& Medicine, 66(5), 1019-1033.

Marsden, P. V., Kalleberg, A. L., \& Cook, C. R. (1993). Gender differences in organizational commitment influences of work positions and family roles. Work and Occupations, 20(3), 368-390.

Matusik, S. F., \& Mickel, A. E. (2011). Embracing or embattled by converged mobile devices? Users' experiences with a contemporary connectivity technology. Human Relations, 64(8), 1001-1030. 
Maume, D. J., \& Purcell, D. A. (2007). The 'over-paced' American: Recent trends in the intensification of work. Workplace Temporalities. Research in the Sociology of Work, 17, $251-283$.

Mirowsky, J., \& Ross, C. E. (2007). Creative work and health. Journal of Health and Social Behavior, 48(4), 385-403.

Mirowsky, J., \& Ross, C. E. (2005). Education, cumulative advantage, and health. Ageing International, 30(1), 27-62.

Mirowsky, J., \& Ross, C. E. (2003). Social causes of psychological distress. Hawthorne, New York: Aldine De Gruyter.

Moen, P. (2015). An institutional/organizational turn: getting to work-life quality and gender equality. Work and Occupations, 42(2), 174-182.

Moen, P., Lam J., Ammons, S., \& Kelly, E. L. (2013). Time work by overworked professionals: strategies in response to the stress of higher status. Work and Occupations, (2), 79-114.

Moen, P. \& Roehling, P. (2005). The career mystique: Cracks in the American Dream. Lanham: Rowman and Littlefield.

Munsch, C. L., Ridgeway, C. L., \& Williams, J. C. (2014). Pluralistic ignorance and the flexibility bias: understanding and mitigating flextime and flexplace bias at work. Work and Occupations, 41(1), 40-62.

Olson-Buchanan, J. B., \& Boswell, W. R. (2006). Blurring boundaries: Correlates of integration and segmentation between work and nonwork. Journal of Vocational Behavior, 68, 432445.

Pearlin, L. (1983). Role strains and personal stress. In H. B. Kaplan (ed.), Psychosocial stress: trends in theory and research, (pp. 3 -32), New York: Academic Press.

Perlow, L. A., \& Kelly, E. L. (2014). Toward a model of work redesign for better work and 
better life. Work and Occupations, 41(1), 111-134.

Pleck, J. H. (1977). The work-family role system. Social problems, 24, 417-427.

Reskin, B. F., \& Ross, C. E. (1992). Jobs, authority, and earnings among managers: the continuing significance of sex. Work and Occupations, 19(4), 342-365.

Ross, C. E., \& Mirowsky, J. (2010). Why education is the key to socioeconomic differentials in health. Handbook of medical sociology, 33-51.

Ruppanner, L. \& Huffman, M. L. (2014). Blurred boundaries: gender and work-family interference in cross-national context. Work and Occupations, 41(2), 210-236.

Schieman, S. (2013). Job-related resources and the pressures of working life. Social Science Research, 42(2), 271-282.

Schieman, S., Schafer, M. H., \& McIvor, M. (2013). The rewards of authority in the workplace: do gender and age matter? Sociological Perspectives, 56(1), 75-96.

Schieman, S., \& Reid, S. (2009). Job authority and health: Unraveling the competing suppression and explanatory influences. Social Science \& Medicine, 69(11), 1616-1624.

Schieman, S., Milkie, M. A., \& Glavin, P. (2009). When work interferes with life: Worknonwork interference and the influence of work-related demands and resources. American Sociological Review, 74, 966-988.

Schieman, S., \& Glavin, P. (2008). Trouble at the border? Gender, flexibility at work, and the work-home interface. Social Problems, 55, 590-611.

Sloan, M. M. (2012). Unfair treatment in the workplace and worker well-being: the role of coworker support in a service work environment. Work and Occupations, 39(1), 3-34.

Smith, R A. (2002). Race, gender, and authority in the workplace: Theory and research. Annual Review of Sociology, 28, 509-542. 
Thoits, P. A. (1995). Stress, coping, and social support processes: Where are we? What next?. Journal of Health and Social Behavior, 53-79.

Towers, I., Duxbury, L., Higgins, C., \& Thomas, J. (2006). Time thieves and space invaders: technology, work and the organization. Journal of Organizational Change Management, 19(5), 593-618.

Townsend, N. (2002). Cultural contexts of father involvement. Handbook of father involvement: Multidisciplinary perspectives, 249-277.

Valcour, P. M., \& Hunter, L. W. (2005). Technology, organizations, and work-life integration. In E. E. Kossek \& S. J. Lambert (Eds.) Work and life integration: Organizational, cultural, and individual perspectives, (pp. 61 -84). Mahwah, NJ: Lawrence Erlbaum Associates.

Van den Broeck, A., Vansteenkiste, M., De Witte, H., \& Lens, W. (2008). Explaining the relationships between job characteristics, burnout, and engagement: The role of basic psychological need satisfaction. Work \& Stress, 22(3), 277-294.

Voydanoff, P. (2005). Consequences of boundary-spanning demands and resources for work-tofamily conflict and perceived stress. Journal of Occupational Health Psychology, 10, 491503.

Voydanoff, P. (2007). Work, family, and community: Exploring interconnections. Mahwah, NJ: Lawrence Erlbaum.

Wheaton, B. (1985). Models for the stress-buffering functions of coping resources. Journal of Health and Social Behavior, 26, 352-364.

Wheaton, B. (1996). The domains and boundaries of stress concepts. In H. B. Kaplan (Ed.), Psychosocial stress: Perspectives on structure, theory, life-course, and methods (pp. 2970). New York: Academic Press. 
Williams, J. (2000). Unbending gender: Why family and work conflict and what to do about it. New York: Oxford University Press.

Winship, C., \& Radbill, L. (1994). Sampling weights and regression analysis. Sociological Methods \& Research, 23(2), 230-257.

Winslow, S. (2005). Work-family conflict, gender, and parenthood, 1977-1997. Journal of Family Issues, 26(6), 727-755.

Wright, E. O., Baxter, J., \& Birkelund, G. E. (1995). The gender gap in workplace authority: A cross-national study. American Sociological Review, 60, 407-435.

Yaish, M. \& Stier, H. (2009). Gender inequality in job authority: A cross-national comparison of 26 countries. Work and Occupations, 36(4), 343-366.

\section{AUTHOR BIOGRAPHIES}

Scott Schieman is professor and Canada Research Chair in the department of sociology at the University of Toronto. His research focuses on the social psychology of inequality and its relationship to health outcomes. He is the lead investigator of the Canadian Work, Stress, and Health study (CANWSH), a national longitudinal study of workers.

Paul Glavin is an assistant professor of sociology at McMaster University. His research examines the social determinants of worker well-being, and the ways in which employment experiences involving control and uncertainty contribute to social inequalities in mental health. 
Appendix Table. Descriptive Statistics for Men and Women

\begin{tabular}{lcc}
\hline & $\begin{array}{c}\text { Men } \\
(\mathrm{N}=1788)\end{array}$ & $\begin{array}{c}\text { Women } \\
(\mathrm{N}=2739)\end{array}$ \\
\hline Role Blurring & 2.384 & 2.329 \\
Job Pressure & $2.927^{*}$ & 3.042 \\
Statuses & & \\
Education & $4.622^{*}$ & 4.985 \\
Professional & $.321^{*}$ & .402 \\
Supervisor & .294 & .304 \\
Manager & $.195^{*}$ & .139 \\
Personal Income & $63267.29^{*}$ & 46266.85 \\
Job Autonomy & $2.033^{*}$ & 1.933 \\
Some Schedule Control & $.376^{*}$ & .367 \\
Full Schedule Control & $.121^{*}$ & .079 \\
Challenging Work & $3.229^{*}$ & 3.319 \\
Control Variables & & \\
Age & .39 .724 & 39.597 \\
Married & .388 & .359 \\
Children at Home & $.381^{*}$ & .434 \\
Private Sector Job & $.716^{*}$ & .518 \\
Full-Time & .622 & .623 \\
Overwork & $.203^{*}$ & .104 \\
\hline * Difference between men and women is significant at $p<.01$ (two-tailed test).
\end{tabular}


TABLE 1. Role Blurring Regressed on Job Pressure, Statuses, and Two-Way Interactions $(\mathrm{N}=4,527)$

\begin{tabular}{|c|c|c|c|c|c|c|c|}
\hline & 1 & 2 & 3 & 4 & 5 & 6 & 7 \\
\hline \multicolumn{8}{|l|}{ Job Pressure } \\
\hline Job Pressure & $.254^{* * *}$ & $.259^{* * *}$ & $.220^{* * *}$ & $.225^{* * *}$ & $.217^{* * *}$ & $.223^{* * *}$ & $.221^{* * *}$ \\
\hline \multicolumn{8}{|l|}{ Statuses } \\
\hline Education & $.073^{* * *}$ & $.077^{* * *}$ & $.073^{* * *}$ & $.072^{* * *}$ & $.073^{* * *}$ & $.073^{* * *}$ & $.072^{* * *}$ \\
\hline Professional & $.141^{* * *}$ & $.133^{* * *}$ & $.135^{* * *}$ & $.144^{* * *}$ & $.135^{* * *}$ & $.142^{* * *}$ & $.146^{* * *}$ \\
\hline Supervisora & $.149^{* * *}$ & $.148^{* * *}$ & $.149^{* * *}$ & $.157^{* * *}$ & $.153^{* * *}$ & $.151^{* * *}$ & $.148^{* *}$ \\
\hline Managera & $.414^{* * *}$ & $.410^{* * * *}$ & $.412^{* * *}$ & $.394^{* * *}$ & $.407^{* * *}$ & $.415^{* * *}$ & $.409^{* * *}$ \\
\hline Income Quartile $2 \mathrm{~b}$ & -.034 & -.030 & -.031 & -.031 & -.027 & -.034 & -.030 \\
\hline Income Quartile 3b & -.005 & -.002 & -.004 & -.001 & .007 & -.007 & -.004 \\
\hline Income Quartile $4 \mathrm{~b}$ & $.158^{* *}$ & $.158^{* *}$ & $.153^{* *}$ & $.155^{* * *}$ & $.159^{* *}$ & $.160^{* *}$ & $.152^{*}$ \\
\hline Job Autonomy & $.075^{* *}$ & $.076^{* *}$ & $.076^{* *}$ & $.075^{* *}$ & $.075^{* *}$ & $.079^{* * *}$ & $.074^{*}$ \\
\hline Job Autonomy² & $.044^{*}$ & $.044^{*}$ & $.046^{*}$ & $.048^{*}$ & $.047^{*}$ & $.044^{*}$ & $.048^{*}-x-10$ \\
\hline Some Schedule Control c & $.120^{* * *}$ & $.120^{* * *}$ & $.125^{* * *}$ & $.120^{* * *}$ & $.116^{* * *}$ & $.121^{* * *}$ & $.126^{* *}$ \\
\hline Full Schedule Control c & $.158^{* *}$ & $.164^{* *}$ & $.169^{* *}$ & $.167^{* *}$ & $.160^{* *}$ & $.160^{* *}$ & $.167^{*}$ \\
\hline Challenging Work & $.114^{* * *}$ & $.115^{* * *}$ & $.115^{* * *}$ & $.117^{* * *}$ & $.113^{* * *}$ & $.116^{* * *}$ & $.115^{* *-}$ \\
\hline \multicolumn{8}{|l|}{ Interaction Terms } \\
\hline \multicolumn{8}{|l|}{ Job Pressure $\times$} \\
\hline Education & - & $.029^{* * *}$ & - & - & - & - & - \\
\hline Professional & - & - & $.098^{* * *}$ & - & - & - & - \\
\hline Supervisor & - & - & - & .028 & - & - & - \\
\hline Manager & - & - & - & $129^{* * *}$ & - & - & - \\
\hline Income Quartile 2 & - & - & - & - & -.015 & - & - \\
\hline Income Quartile 3 & - & - & - & - & .059 & - & - \\
\hline Income Quartile 4 & - & - & - & - & $.127^{* * *}$ & - & - \\
\hline Job Autonomy & - & - & - & - & - & .018 & - \\
\hline Job Autonomy² & - & - & - & - & - & $.044^{* *}$ & - \\
\hline Some Schedule Control & - & - & - & - & - & - & $.083^{*}$ \\
\hline Full Schedule Control & - & - & - & - & - & - & .038 \\
\hline \multicolumn{8}{|l|}{ Control Variables } \\
\hline Women & $-.090^{* *}$ & $-.094^{* *}$ & $-.092^{* *}$ & $-.088^{* *}$ & $-.092^{* *}$ & $-.087^{* *}$ & $-.090^{* *}$ \\
\hline Age & $-.005^{* * *}$ & $-.005^{* * *}$ & $-.005^{* * *}$ & $-.005^{* * *}$ & $-.005^{* * *}$ & $-.005^{* * *}$ & $-.005^{* * *}$ \\
\hline Married & -.024 & -.023 & -.022 & -.024 & -.022 & -.023 & -.026 \\
\hline Children at Home & $.071^{*}$ & $.072^{*}$ & $.069^{*}$ & $.069^{*}$ & $.066^{*}$ & $.069^{*}$ & $.070^{*}$ \\
\hline Private Sector Job & -.007 & -.005 & -.006 & -.005 & -.007 & -.007 & -.009 \\
\hline Full-Timed & $-.183^{* * *}$ & $-.183^{* * *}$ & $-.177^{* * *}$ & $-.181^{* * *}$ & $-.172^{* * *}$ & $-.183^{* * *}$ & $-181^{* * *}$ \\
\hline Overwork ${ }^{\mathrm{d}}$ & $.253^{* * *}$ & $.240^{* * *}$ & $.244^{* * *}$ & $.240^{* * *}$ & $.246^{* * *}$ & $.254^{* * *}$ & $.245^{* * *}$ \\
\hline Constant & 2.437 & 2.437 & 2.420 & 2.423 & 2.424 & 2.433 & 2.427 \\
\hline $\mathrm{R}^{2}$ & .377 & .380 & .380 & .380 & .381 & .379 & .379 \\
\hline
\end{tabular}

${ }^{*} p<.05 ;{ }^{* *} p<.01 ;{ }^{* * *} p<.001$ (two-tailed test).

${ }^{a}$ Compared to workers (no job authority).

${ }^{b}$ Compared to income quartile 1.

${ }^{c}$ Compared to no schedule control.

${ }^{d}$ Compared to part-time work.

Note: Unstandardized regression coefficients shown in table (standard errors are available upon request) 
TABLE 2. Three-Way Interactions Predicting Role Blurring $(\mathrm{N}=4,527)$

\begin{tabular}{lc}
\hline Does the interaction between job pressure and professional differ by gender? \\
Job Pressure & $.186^{* * *}$ \\
Professional & $.197^{* * *}$ \\
Women & .038 \\
Job Pressure $\times$ Professional & $.170^{* * *}$ \\
Job Pressure $\times$ Women & .072 \\
Professional $\times$ Women & $-.111^{*}$ \\
Job Pressure $\times$ Professional $\times$ Women & $-.132^{*}$ \\
\hline & \\
Does the interaction between job pressure and authority differ by gender? & $.196^{* * *}$ \\
Job Pressure & $.148^{* * *}$ \\
Supervisor $a$ & $.330^{* * *}$ \\
Manager $a$ & $-.103^{*}$ \\
Women & .020 \\
Job Pressure $\times$ Supervisor & .060 \\
Job Pressure $\times$ Women & .008 \\
Supervisor $\times$ Women & .014 \\
Job Pressure $\times$ Supervisor $\times$ Women & $.224^{* * *}$ \\
Job Pressure $\times$ Manager & $.166^{*}$ \\
Manager $\times$ Women & $-.220^{* *}$ \\
Job Pressure $\times$ Manager $\times$ Women & \\
\hline
\end{tabular}

Does the interaction between job pressure and income differ by gender?

Job Pressure

Income Quartile $2 b$

Income Quartile $3 b$

Income Quartile $4^{b}$

Women

Job Pressure $\times$ Women

Job Pressure $\times$ Income Quartile 2

Income Quartile $2 \times$ Women

Job Pressure $\times$ Income Quartile $2 \times$ Women

Job Pressure $\times$ Income Quartile 3

Income Quartile $3 \times$ Women

Job Pressure $\times$ Income Quartile $3 \times$ Women

Job Pressure $\times$ Income Quartile 4

Income Quartile $4 \times$ Women

Job Pressure $\times$ Income Quartile $4 \times$ Women
$.179^{* * *}$

$-.053$

$-.038$

.126

$-.125$

.070

$-.073$

.030

.097

.095

.104

$-.075$

$.194^{* * *}$

.112

$-.172^{*}$

${ }^{*} p<.05 ;{ }^{* *} p<.01 ;{ }^{* * *} p<.001$ (two-tailed test).

a Compared to workers (no job authority).

${ }^{b}$ Compared to income quartile 1 .

Note: Unstandardized regression coefficients shown in table (standard errors are available upon request). Results are based on analyses that included all variables from model 1 of Table 1. 


\section{FIGURE 1. The Pressure-Status Nexus and Blurred Boundaries}

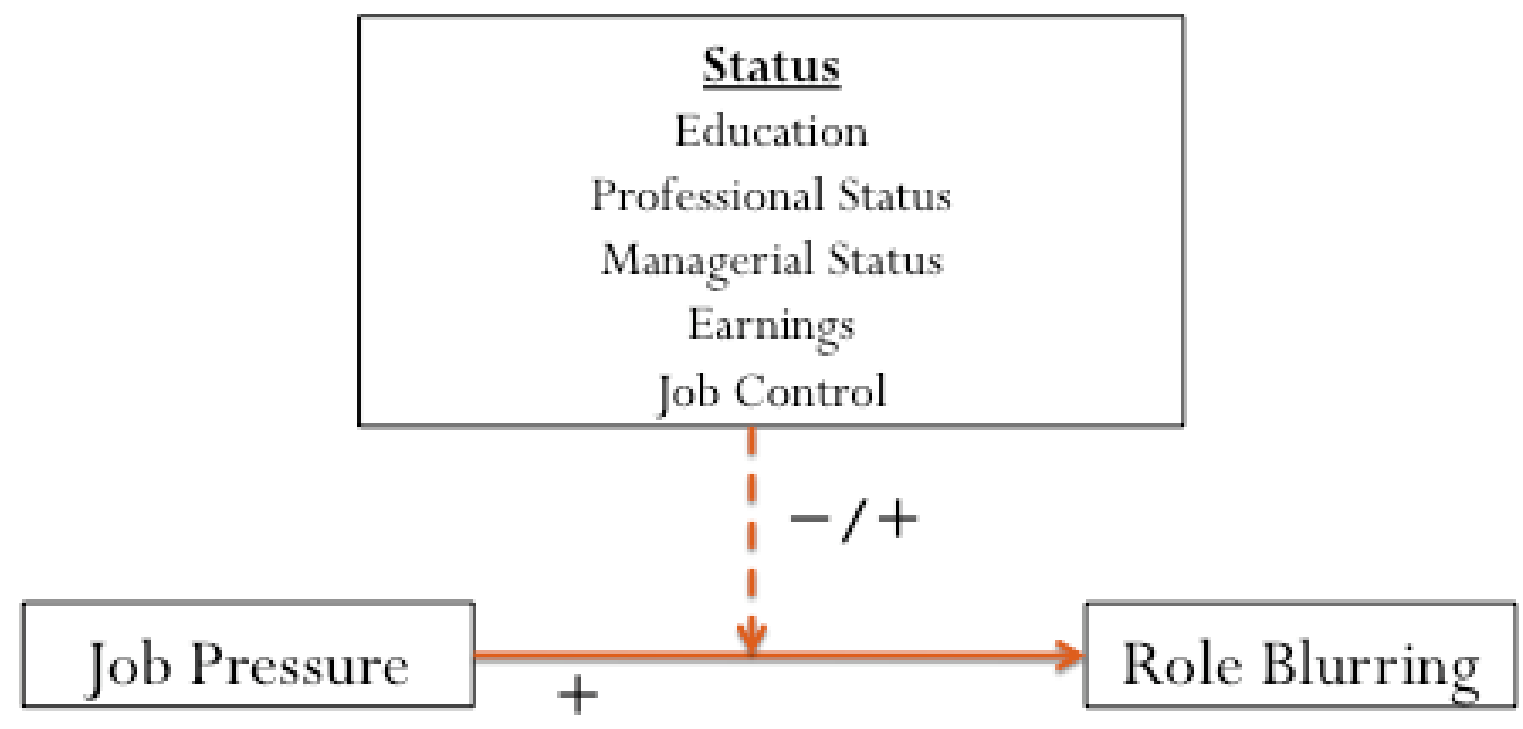

Note: For the dashed arrow, the negative sign represents the status advantage hypothesis and the positive sign represents the stress of higher status hypothesis. 


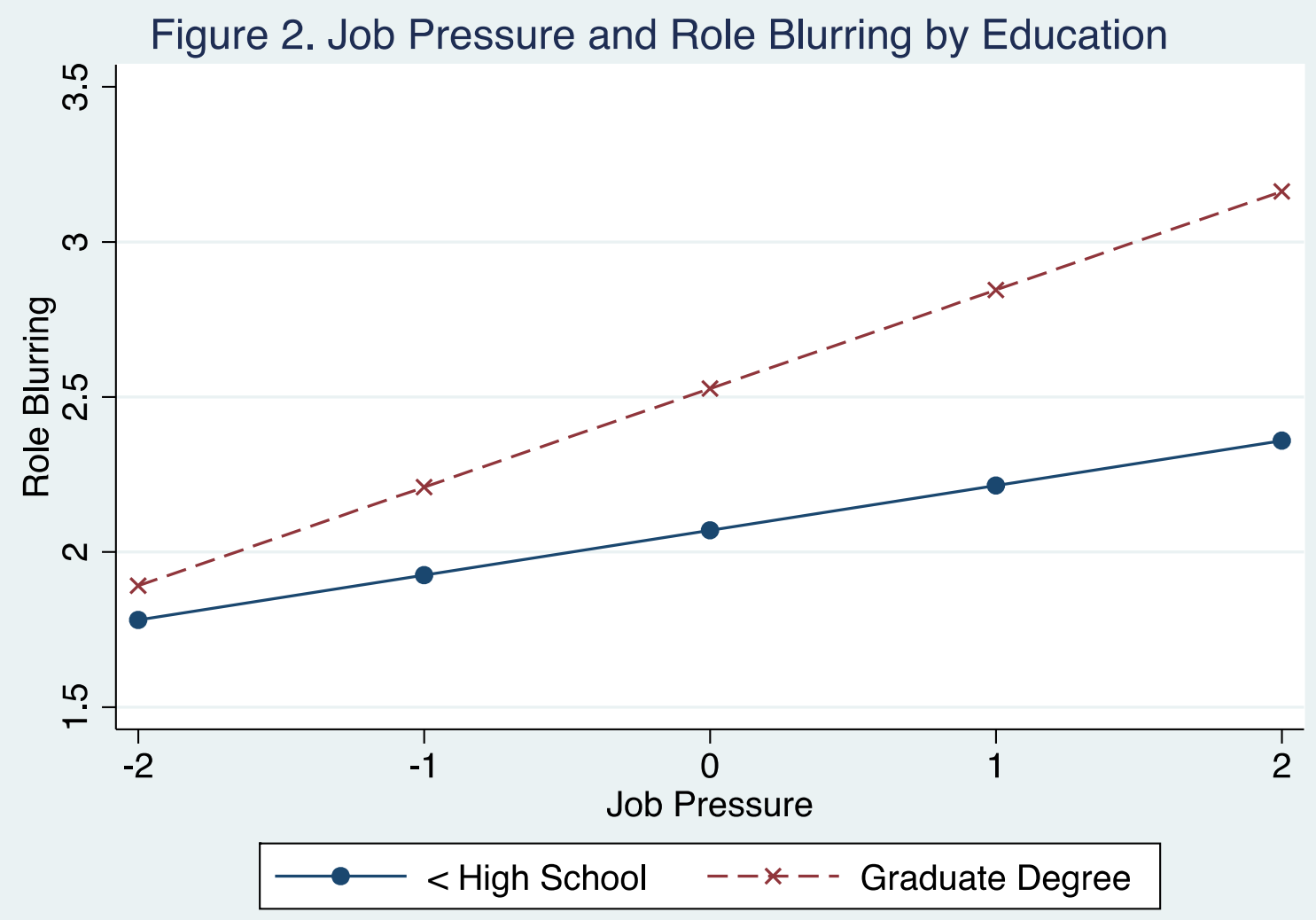


Figure 3. Job Pressure and Role Blurring by Gender and Professional Status

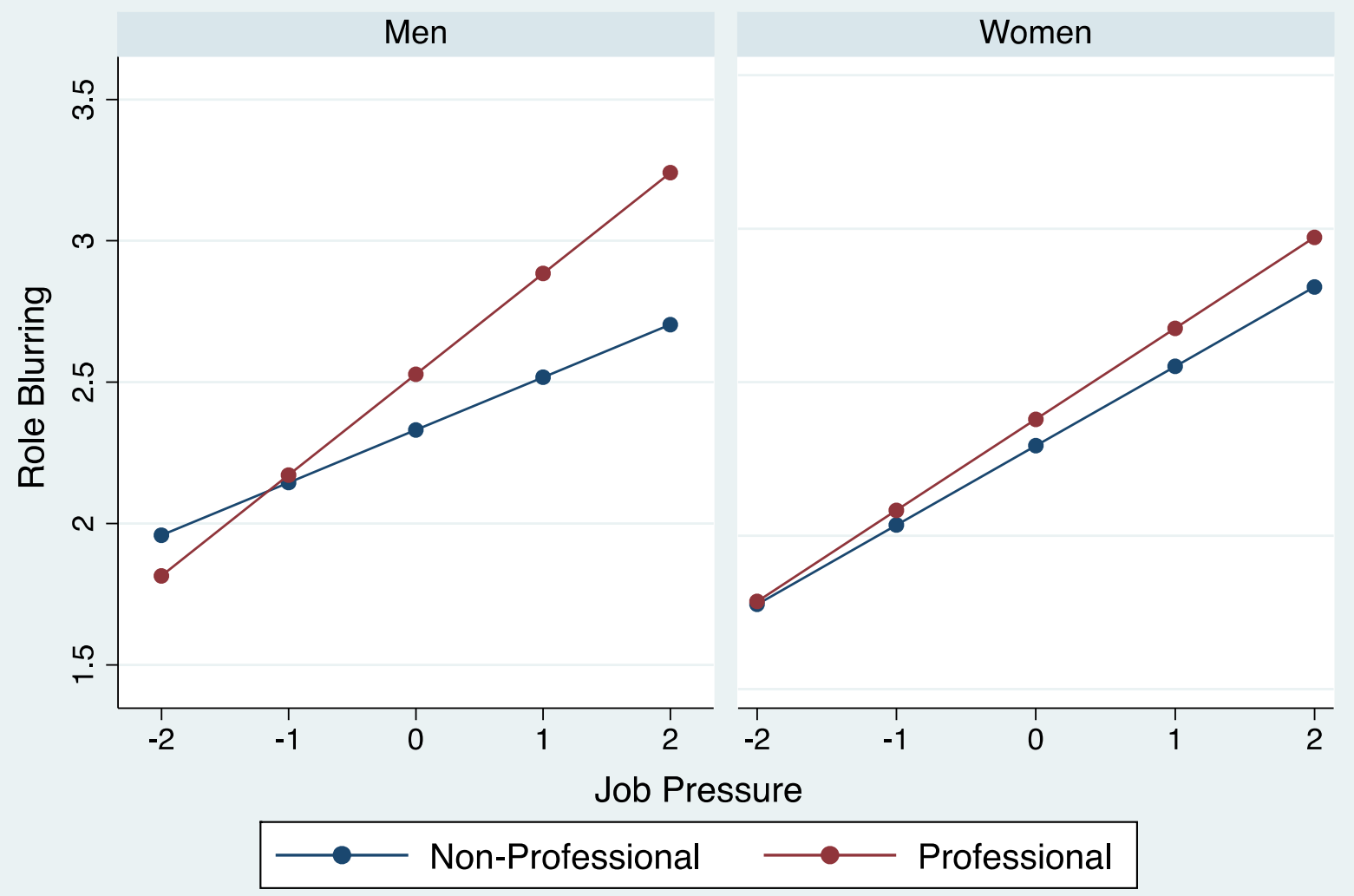


Figure 4. Job Pressure and Role Blurring by Gender and Job Authority

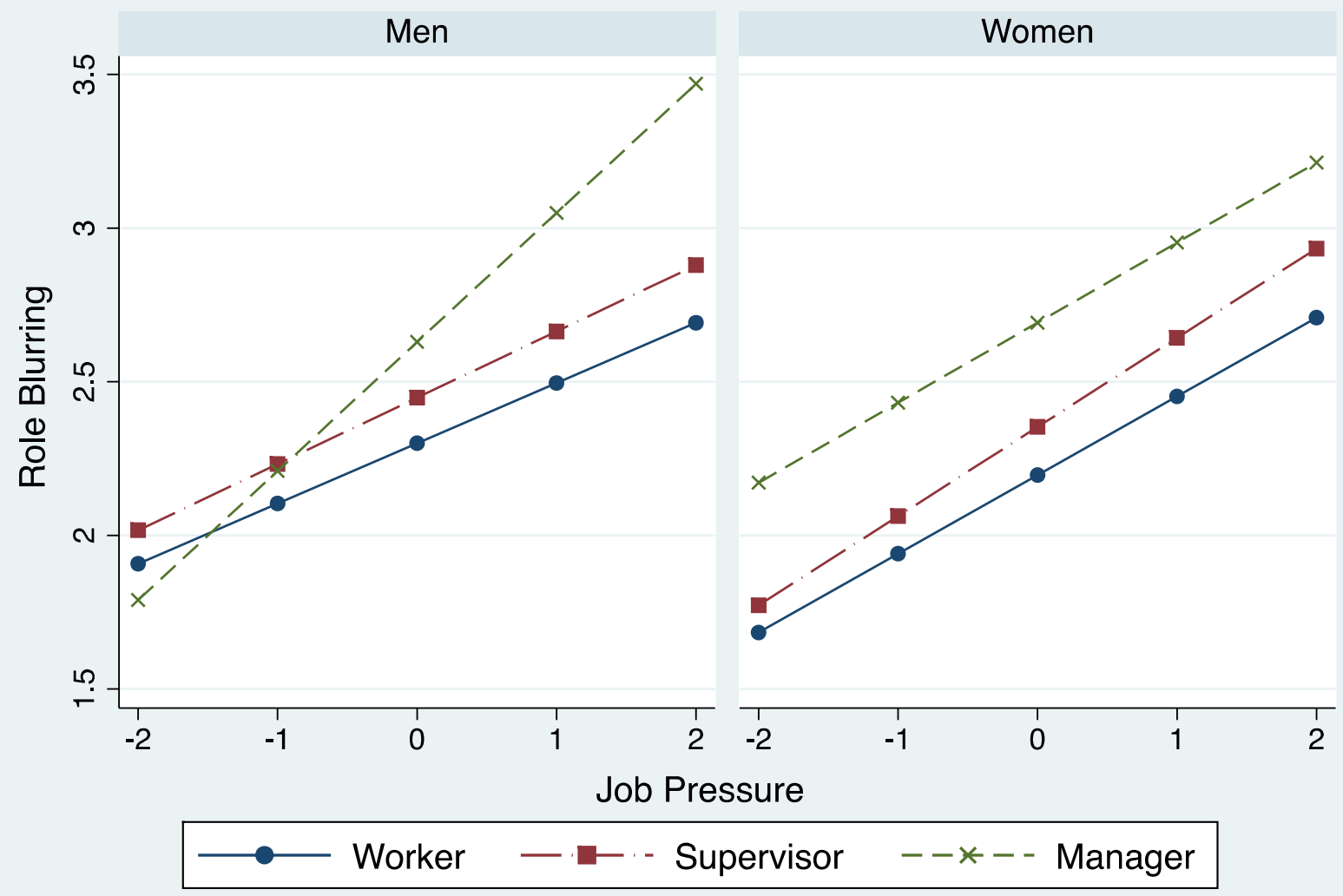


Figure 5. Job Pressure and Role Blurring by Gender and Income

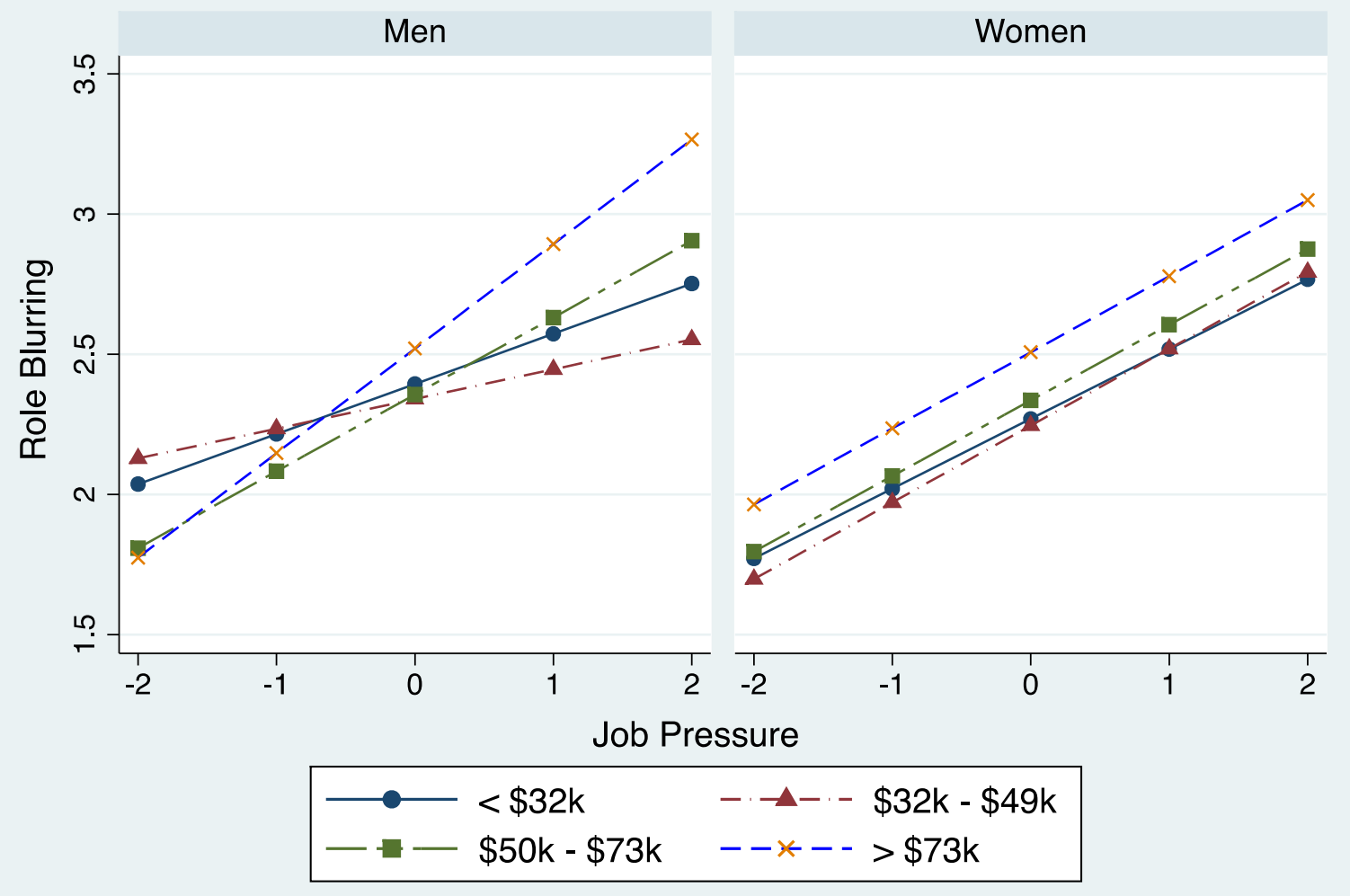

